\title{
High interleukin-4 expression and interleukin-4 gene polymorphisms are associated with susceptibility to human paracoccidioidomycosis
}

\author{
Mônica Sawan Mendonça', Terezinha S Peraçolli², Mário León Silva-Vergara', Sílvio C Ribeiro', \\ Rafael Faria Oliveira', Rinaldo Poncio Mendes ${ }^{2}$, Virmondes Rodrigues Jr¹/+ \\ 1Universidade Federal do Triângulo Mineiro, Laboratório de Imunologia, Uberaba, MG, Brasil \\ ${ }^{2}$ Universidade Estadual Paulista, Faculdade de Medicina de Botucatu, Botucatu, SP, Brasil
}

Paracoccidioidomycosis (PCM) is caused by dimorphic fungi from the Paracoccidioides brasiliensis complex. Previous studies have demonstrated that the severity of disease is associated with a T-helper 2 immune response characterised by high interleukin (IL)-4 production. In the present study we analysed two polymorphisms in the IL-4 gene (-590 C/T and intron-3 microsatellite) in 76 patients with PCM and 73 control subjects from an endemic area. The production of IL-4 by peripheral blood mononuclear cells after antigen or phytohaemagglutinin stimulation was determined by ELISA. A significant correlation was observed between the RP2/RP2 intron-3 genotype and infection with Paracoccidioides sp. $(p=0.011)$, whereas the RPI/RP1 genotype was correlated with resistance. No significant correlation was observed for the IL-4 promoter polymorphism. Furthermore, the low IL-4 expression observed in the control group compared with patients was associated with the RPI/RPI genotype. These results suggest that IL-4 polymorphisms might be associated with the ability of the host to control Paracoccidioides sp. infection. The relevance of this polymorphism is supported by the observation that patients with disease produce high levels of IL-4 following mitogen or antigen stimulation. The IL-4 gene is located in the cytokine cluster region of chromosome 5 where other polymorphisms have also been described.

Key words: gene polymorphism - IL-4 - Paracoccidioides brasiliensis - paracoccidioidomycosis

Paracoccidioidomycosis (PCM) is the most prevalent systemic mycosis in Latin America and is endemic in Brazil, Argentina, Venezuela and Colombia (Restrepo 1985, Blotta et al. 1999). The disease is caused by the dimorphic fungi Paracoccidioides brasiliensis and Paracoccidioides lutzii. After invasion, the fungi are either immediately destroyed or overcome the local defences of the host and begin multiplication, thereby causing initial injury. In humans, the disease is characterised by a broad spectrum of clinical manifestations that range from localised mucocutaneous lesions to widespread manifestations involving the mononuclear phagocyte system (Shikanai-Yasuda et al. 2006). Patients with active disease present high levels of specific antibodies, but no delayed-type hypersensitivity reaction to specific antigen stimulation. These properties are closely related to the outcome of infection and are used for the clinical follow-up of treated patients and as criteria for cure of the disease (Marques 2012).

Cytokines are pleiotropic molecules that regulate many aspects of the immune response and inflammatory reactions (Fitzgerald et al. 2001). T-helper (Th) cells are the major source of regulatory cytokines and can be divided

doi: 10.1590/0074-02760150197

Financial support: FAPEMIG -NIDR, CNPq, FUNEPU

+ Corresponding author: vrodrigues@mednet.com.br

Received 18 May 2015

Accepted 13 July 2015 into at least two distinct polar subpopulations according to their cytokine pattern (Bernard et al. 1997). In humans, Th1 cells produce interferon (IFN) $-\gamma$, tumour necrosis factor (TNF) $-\beta$ and TNF- $\alpha$, whereas Th2 cells produce interleukin (IL)-4, IL-5 and IL-13. Because of their strong influence on immune effector mechanisms, the preferential activation of one population or another is associated with resistance/susceptibility to infectious diseases.

Previous studies have demonstrated that PCM is associated with a Th2 immune response that is characterised by high IL-4 production after antigen or phytohaemagglutinin (PHA) stimulation (Mello et al. 2002, Cavassani et al. 2011). Because certain gene polymorphisms are able to modulate their expression, genetic variants may be associated with resistance or susceptibility to infectious diseases (Bozzi et al. 2006). IL-4 is located on chromosome 5 in the 5q31-q33 region, close to the genes of many other regulatory cytokines (Fitzgerald et al. 2001). IL-4 gene polymorphisms have been described in association with some noninfectious diseases, such as rheumatoid arthritis, asthma and atopy (Burchard et al. 1999, Cantagrel et al. 1999, Rosenwasser 1999, Nie et al. 2013), and with infectious diseases, such as dental infection (Michel et al. 2001, Kang et al. 2003, Pontes et al. 2003, Scarel-Caminaga et al. 2003), cases of malaria (Verra et al. 2004) and human immunodeficiency virus (HIV)-1 infection (Nakayama et al. 2002, Modi et al. 2003).

In this study, we selected IL-4 as a candidate gene due to its biological properties in the regulation of immune responses, some of which have been observed in PCM patients, including high serum levels of immunoglobulins and the absence of delayed type hypersensitivity to $P$. brasiliensis antigens. Furthermore, we and oth- 
ers have observed that IL-4 was produced at high levels by peripheral blood mononuclear cells (PBMC) after antigen or PHA stimulation (Mello et al. 2002, Cavassani et al. 2011). We analysed two polymorphisms, one in the promoter region and the second in intron-3 of the $I L-4$ gene, both in patients with PCM and in control subjects from an endemic area as well as the expression of IL-4 in PBMC supernatants after stimulation with P. brasiliensis crude antigens and PHA.

\section{SUBJECTS, MATERIALS AND METHODS}

Subjects - The study was conducted at two Brazilian centres: the General Hospital of Federal University of Triângulo Mineiro (UFTM) and the University Hospital of Botucatu Medical School, São Paulo State University (UNESP). To be eligible for the study, patients had to give informed consent and to have confirmed PCM. The study protocol was reviewed and approved by the Research Ethical Committee of UFTM. All participants provided written informed consent to participate in this study.

Seventy-six patients (20 women and 56 men), aged $33.2 \pm 14.1$ years, with a diagnosis of PCM were included in this study. The diagnosis was confirmed via the identification of typical P. brasiliensis yeast forms through mycological examination, cell-block preparation and/or histopathological examination of clinical specimens. Patients were included regardless of the phase of disease, i.e., active (before treatment), under treatment and cured with or without sequelae. The control group consisted of 73 healthy subjects from endemic areas $(20$ women and 53 men), aged $33.9 \pm 12.0$ years, who had a positive skin test to paracoccidioidin and a negative reaction to histoplasmin and who showed no present or past symptoms that were compatible with PCM.

The skin tests were performed using paracoccidioidin and histoplasmin. Paracoccidioidin was prepared as sterile polysaccharide antigen at the Department of Pathology, Botucatu Medical School, UNESP, from a pool of several Paracoccidioides sp. strains in the yeast form. Histoplasmin was prepared as a sterile culture filtrate from the mycelial growth of Histoplasma capsulatum var. capsulatum strains B-679 and A-811 at the Evandro Chagas Clinical Research Institute, Oswaldo Cruz Foundation. The tests were carried out according to classical protocols (Gascan et al. 1991, Rosenwasser 1999).

IL-4 expression - Blood samples $(10 \mathrm{~mL})$ were collected from the patients and PBMCs were isolated by Ficoll-Paque centrifugation $(400 \mathrm{~g}, 20 \mathrm{~min}$ at room temperature), washed three times in RPMI medium and resuspended in RPMI (Gibco, USA) supplemented with 50 $\mathrm{mM}$ 2-ME, $2 \mathrm{mM}$ L-glutamine, $40 \mu \mathrm{g} / \mathrm{mL}$ gentamicin and $10 \%$ foetal calf serum (complete medium).

For supernatant production, $2 \times 10^{6}$ cells per well per $\mathrm{mL}$ were cultured in a 24 -well microplate in the presence of medium alone, $5 \mu \mathrm{g} / \mathrm{mL}$ PHA, or $5 \mu \mathrm{g} / \mathrm{mL}$ cellfree antigens from a pool of several Paracoccidioides spp strains in the yeast form. The plates were incubated at $37^{\circ} \mathrm{C}$ in a $5 \% \mathrm{CO}_{2}$ atmosphere for $48 \mathrm{~h}$ and the supernatants were collected, centrifuged and stored at $-70^{\circ} \mathrm{C}$ until IL-4 production analysis. IL-4 was titrated by ELI-
SA in 96-well microplates (Nunc, Denmark) using commercial monoclonal antibody pairs (Mabtech, Sweden). The sensitivity of the assay was $2 \mathrm{pg} / \mathrm{mL}$.

IL-4 gene polymorphism - Blood samples $(10 \mathrm{~mL})$ were collected from the patients and leukocytes were purified by red blood cell lysis. Genomic DNA was purified using the DNAzol reagent. The two regions of interest were amplified by polymerase chain reaction (PCR) using the following primers: 5'-AGGTGAAAGGGGAAAGC-3' and 5'-CTGTTCACCTCAACTGCTCC-3' (Bozzi et al. 2006) for analysis of the intron-3 microsatellite and 5'-ACTAGGCCTCACCTGATACG-3' and 5'GTTGTAATGCAGTCCTCCTG-3' (Fitzgerald et al. 2001) for the SNP at -590 . In the case of the $C / T$ substitution at position -590 , the PCR product was digested with $A v a$ II. The resulting products were analysed by polyacrylamide gel electrophoresis.

Statistical analysis - Genotype frequencies were analysed statistically by the chi-square test, with the level of significance set at $5 \%(\mathrm{p}<0.05)$. The association of the IL-4 levels with disease or IL-4 genotypes was analysed using the Mann-Whitney $U$ test. Statistical analysis was performed using the GraphPad Prism software (GraphPad Software Inc, USA).

\section{RESULTS}

Intron-3 polymorphism - The intron-3 polymorphism of the $I L-4$ gene was determined in 149 subjects (76 patients and 73 controls) and three genotypes (RP2/ RP2, RP2/RP1 and RP1/RP1) were detected. A significantly lower frequency of the RP1/RP1 genotype was observed in patients (5.2\%) compared with the control group (23.3\%). In contrast, the frequency of the RP2/ RP2 genotype was $53.9 \%$ in patients and $37 \%$ in controls [p $=0.0042$; odds ratios (OR): RP2RP2 x RP1RP1 $=6.454 ; 95 \%$ confidence interval $(\mathrm{CI}): 1.958-21.28]$. The frequency of the heterozygous RP1/RP2 genotype was similar in both patients and controls (Table I).

The association of RP2 with disease was confirmed by the relative risk of 6.454 (CI: 1.958-21.28) when comparing RP2RP2 with RP1RP1. The frequencies of the RP1 and RP2 alleles were 38.23 and $57.65 \%$, respectively, in patients and $61.77 \%$ and $42.35 \%$ in the control

\section{TABLE I}

Distribution of the frequency of genotypes

$\mathrm{RP} 1 / \mathrm{RP} 1, \mathrm{RP} 2 / \mathrm{RP} 1$ and RP2/RP2 in controls individuals and patients infected with Paracoccidioides sp.

\begin{tabular}{lcccc}
\hline Genotypes & $\begin{array}{c}\text { RP1/RP1 } \\
\mathrm{n}(\%)\end{array}$ & $\begin{array}{c}\mathrm{RP} 2 / \mathrm{RP} 1 \\
\mathrm{n}(\%)\end{array}$ & $\begin{array}{c}\mathrm{RP} 2 / \mathrm{RP} 2 \\
\mathrm{n}(\%)\end{array}$ & $\begin{array}{c}\text { Total } \\
\mathrm{n}\end{array}$ \\
\hline Controls & $17(23.3)$ & $29(39.7)$ & $27(37)$ & 73 \\
Patients & $4(5.2)$ & $31(40.7)$ & $41(53.9)$ & 76 \\
\hline Total & $21(14.09)$ & $60(40.27)$ & $68(45.64)$ & 149 \\
\hline
\end{tabular}

$\mathrm{p}=0.0042$; odds ratios: $\mathrm{RP} 2 \mathrm{RP} 2 \times \mathrm{RP} 1 \mathrm{RP} 1=6,454$; $95 \%$ confidence interval: 1.958-21.28. 


\section{TABLE II}

Distribution of the frequency of genotypes CC, $\mathrm{CT}$ and TT in controls individuals and patients infected with Paracoccidioides sp.

\begin{tabular}{lcccc}
\hline Genotypes & $\begin{array}{c}\mathrm{CC} \\
\mathrm{n}(\%)\end{array}$ & $\begin{array}{c}\mathrm{CT} \\
\mathrm{n}(\%)\end{array}$ & $\begin{array}{c}\mathrm{TT} \\
\mathrm{n}(\%)\end{array}$ & $\begin{array}{c}\text { Total } \\
\mathrm{n}\end{array}$ \\
\hline Controls & $15(20.54)$ & $21(28.76)$ & $37(50.68)$ & 73 \\
Patients & $8(10.52)$ & $22(28.95)$ & $46(60.53)$ & 76 \\
\hline Total & $23(15.44)$ & $43(28.86)$ & $83(55.70)$ & 149 \\
\hline
\end{tabular}

$\mathrm{p}=0.2154$.

group, thus demonstrating an association of the RP2 allele with disease $\left(\chi^{2}=10.12 ; \mathrm{p}=0.0015\right)$, with a relative risk of 2.01 (CI: 1.348-3.589).

-590 C/T promoter polymorphism - The $-590 \mathrm{C} / \mathrm{T}$ polymorphism in the promoter region of the $I L-4$ gene was analysed in 149 subjects (76 patients and 73 controls) and three genotypes (CC, TC and TT) were detected. No significant correlation was found between these three genotypes and infection with $P$. brasiliensis. The frequency of genotype CC was $20.54 \%$ in controls and $10.52 \%$ in patients. Genotype TT was present in $50.68 \%$ of the controls and $60.53 \%$ of the patients. The frequency of the heterozygous genotype (CT) was similar in the two groups (Table II). No significant correlation was observed in the genotypes or in the allele frequency between patients and controls.

IL-4 expression - Significantly higher levels of IL-4 were observed in supernatants from patients with disease compared with controls ( $p<0.01$ ) (A in Figure). After PHA stimulation, the IL-4 levels ranged from 32-256 pg/ $\mathrm{mL}$ (median: $74 \mathrm{pg} / \mathrm{mL}$ ) in the supernatants of patients, whereas these levels ranged from undetectable to $41 \mathrm{pg} / \mathrm{mL}$ (median: $10 \mathrm{pg} / \mathrm{mL}$ ) in the control group. In supernatants stimulated with cell-free antigen, the IL-4 levels ranged from $26-66 \mathrm{pg} / \mathrm{mL}$ (median: $40 \mathrm{pg} / \mathrm{mL}$ ) in patients and were below the detection limit in the control group. The analysis of IL-4 production by PBMC after PHA stimulation and grouped according to intron-3 genotype demonstrated that the RP1-1 genotype produced significantly less IL-4 than did RP2-1 and RP2-2 ( $<<0.05)$ (B in Figure).

\section{DISCUSSION}

IL-4 has multiple immune response-modulating functions, including the induction of $\operatorname{IgE}$ production by B lymphocytes and the differentiation of precursor Th cells toward the Th2 subset that mediates humoral immunity. IL-4 also acts as the main antagonist of IFN- $\gamma$ and thus inhibits the activation of macrophages and cell-mediated reactions (Nakayama et al. 2002). A study analysing the cellular immune response in patients with PCM reported a strong Th2 response after stimulation with PHA, which was characterised by high levels of IL-4 and IL-5 (Mello et al. 2002). The resistance to infection is mainly deter- mined by cellular immunity, more specifically by the effective cooperation between $\mathrm{T}$ lymphocytes and macrophages (Franco et al. 1989, Rigobello et al. 2013). In contrast, a Th2 response characterised by high levels of IL-4 has been associated with infection and the development of severe forms of disease (Mello et al. 2002). Elevated levels of IL-4 associated with very low levels of IFN- $\gamma$ seem to lead to the development of an unfavourable specific immune response, such as that observed in patients with the multifocal form of PCM. The results obtained for patients with the unifocal form support this idea, based on the observation of reduced levels of IL-4, elevated levels of IFN- $\gamma$ and a less severe course of the disease (Mello et al. 2002). It is still unclear whether IL-4 and IFN- $\gamma$ are responsible for susceptibility or resistance, respectively, to infection with $P$. brasiliensis. However, such susceptibility and resistance to infectious diseases are likely the result of interactions among multiple factors rather than a single factor (Abel \& Dessein 1997).

In this study, we investigated two $I L-4$ gene polymorphisms in patients with PCM and control subjects from an endemic area: the dimorphic intron-3 polymorphism,
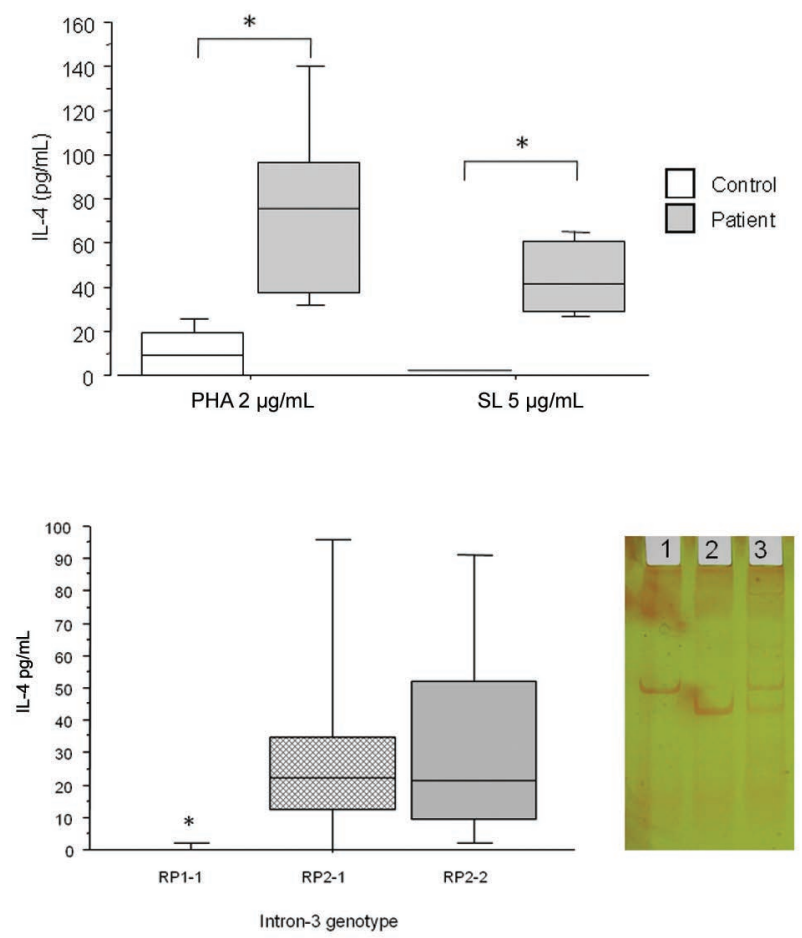

Production of interleukin (IL)-4 by peripheral blood mononuclear cells from patients and control subjects stimulated with phytohaemagglutinin (PHA) or crude soluble Paracoccidioides brasiliensis antigens (A) or on all casuistic (patients and controls) grouped according to intron-3 genotype (B). Horizontal lines represent the median, bars represent the $25-75 \%$ percentiles and vertical line the $10-90 \%$ percentiles. Asterisk mean significance with $\mathrm{p}<0.05$ Mann-Whitney $U$ and Kruskal-Wallis. Lateral panel of B: a representative polyacrylamide gel electrophoresis of intron-3 polymorphism. Line 1: PR2-2; 2: RP1-1; 3: RP2-1. RP1 correspond to $183 \mathrm{bp}$ and RP2 correspond to 253 bp DNA fragments. SL: streptolysin. 
which is represented by a microsatellite in which RP1 corresponds to two repetitions in the 70-bp sequence and RP2 to three repetitions in the same sequence and a polymorphism in the promoter region, which corresponds to a C/T substitution at position -590 (Cantagrel et al. 1999). In the sample studied, the frequency of the RP1/RP1 genotype was four times higher in the control group than in the patient group ( $23.3 \%$ vs. $5.2 \%)$. In contrast, the RP2/ RP2 genotype was observed in $37 \%$ of the controls and $53.9 \%$ of the patients. The frequency of the heterozygous genotype (RP1/RP2) was similar in the two groups. These data indicate a correlation between the presence of the RP2/RP2 genotype and infection, whereas the RP1/ $\mathrm{RP} 1$ genotype is correlated with resistance. With respect to the promoter polymorphism, we did not observe a significant difference between patients and controls.

Furthermore, the present study provides evidence that the expression of IL-4 is up-regulated in patients after antigen and mitogen stimulation, in agreement with data previously published by our group (Mello et al. 2002) and with the findings reported by Cavassani et al. (2011). These data are also supported by the observation that PCM patients exhibit high levels of IgE-specific antibodies (de Britto \& Franco 1994). Moreover, this study provides evidence that PBMC from subjects bearing the RP1-1 genotype at intron-3 are associated with disease protection (OR: RP2RP2 x RP1RP1 $=6.454)$ and produce less IL-4 than do the RP2-1 or RP2-2 genotypes.

However, the small sample size of this study is a limitation. We thus consider that PCM is a lowly endemic disease; all control subjects were from the same endemic area and, upon selection, presented signs of Paracoccidioides sp. exposure based on a positive skin test to paracoccidioidin or the reactivity of serum antibodies to Paracoccidioides sp. antigens.

In humans, the gene encoding IL-4 is located on chromosome 5 in the $5 \mathrm{q} 31$-q33 region, which is the so-called cytokine cluster, where other genes important for the immune system, such as IL-5, IL-9, IL-12, IL-13 and granulocyte-macrophage-colony-stimulating factor, are also found. These cytokines play an important role in the regulation of Th1/Th2 immune responses (Fitzgerald et al. 2001). Case-control studies have provided evidence for a correlation of the intron-3 $I L-4$ promoter polymorphisms with various diseases, such as rheumatoid arthritis (Cantagrel et al. 1999), respiratory and infectious disorders in children (Zhu et al. 2000, Segal \& Hill 2003, Steinke et al. 2003) and early-stage dental infections or susceptibility to dental plaques caused by microorganisms (Michel et al. 2001). The protective effect of the $I L-4$ promoter polymorphism in patients with HIV-1 was demonstrated by the observation that this polymorphism was correlated with viral load in patients in the progressive phase of the disease (Nakayama et al. 2002). This same polymorphism was associated with viral persistence in hepatitis $\mathrm{B}$ virus infection (Saxena et al. 2014). In renal cell carcinoma, this promoter polymorphism was associated with disease development and survival (Kleinrath et al. 2007). With respect to diseases caused by fungi, a correlation between the $I L-4$ gene polymorphism and high levels of vaginal IL-4 was demonstrated in recurrent vulvovaginal candidiasis (Babula et al. 2004). Furthermore, an association was reported between chronic disseminated candidiasis in adult acute leukaemia and the $I L-4$ promoter polymorphism (Choi et al. 2003).

To our knowledge, no functional studies have been performed on the $I L-4$ gene polymorphisms analysed here using construction genes. However, the present results indicate a significant correlation between the intron-3 polymorphism and the occurrence of disease. The marked production of this cytokine was observed in patients with PCM, in agreement with previous findings reported by our group (Mello et al. 2002) and others (Cavassani et al. 2011). In addition, low IL-4 levels were observed in subjects with the polymorphic genotype RP1-1 at intron-3. The $I L-4$ gene is located in the cytokine cluster on chromosome 5 , where other genes such as $I L-5, I L-9, I L-12$ and $I L-13$ are also found and all of these genes have a potential regulatory role in the immune response. $I L-4, I L-13$ and $I L-5$ genes were found to be regulated coordinately by several long-range regulatory elements in a greater than $120 \mathrm{~kb}$ range on chromosome 5 . Thus, the correlation observed might be attributed to another gene located in the region whose polymorphism is in linkage disequilibrium with the polymorphism studied here. Another study evaluating IL-10 and TNF- $\alpha$ gene polymorphisms in PCM demonstrated an association between the IL-10 polymorphism and disease (Bozzi et al. 2006). In the present study, we analysed a larger number of patients and the control subjects were all from endemic areas and were considered to be exposed to Paracoccidioides sp. because they presented a positive reaction to fungal antigens.

The present results indicate a significant correlation between the presence of the RP2/RP2 genotype and $\mathrm{PCM}$, whereas the RP1/RP1 genotype is correlated with resistance and with low production of IL-4. These data support the importance of IL-4 for the determination of susceptibility to Paracoccidioides sp. and open new perspectives for the development or introduction of new therapies for PCM.

\section{REFERENCES}

Abel L, Dessein AJ 1997. The impact of host genetics on susceptibility to human infectious diseases. Curr Opin Immunol 9: 509-516.

Babula O, Lazdäne G, Kroica J, Linhares IM, Ledger WJ, Witkin SS 2004. Frequency of interleukin-4 (IL-4) -589 gene polymorphism and vaginal concentrations of IL-4, nitric oxide and mannosebinding lectin in women with recurrent vulvovaginal candidiasis. Clin Infect Dis 40: 1258-1262.

Bernard G, Mendes-Giannini MJS, Juvenale M, Miranda ET, Duarte AJS 1997. Immunosuppression in paracoccidioidomycosis: T cell hyporesponsiveness to two Paracoccidioides brasiliensis glycoproteins that elicit strong humoral immune response. J Infect Dis 175: 1263-1267.

Blotta MH, Mamomi RL, Oliveira SJ, Nouer SA, Papaiordanou PMO, Gouveia A, Camargo ZP 1999. Endemic regions of paracoccidioidomycosis in Brazil: a clinical and epidemiologic study of 584 cases in the Southeast Region. Am J Trop Med Hyg 61: 390-394.

Bozzi A, Pereira PPN, Reis BS, Goulart MI, Pereira MCN, Pedroso EP, Leite MF, Goes AM 2006. Interleukin-10 and tumor necrosis factor-alfa single nucleotide gene polymorphism frequency in paracoccidioidomycosis. Hum Immunol 67: 931-939. 
Burchard EG, Silverman EK, Rosenwasser LJ, Borish L, Yandava C, Pillari A, Weiss ST, Hasday J, Lilly CM, Ford JG, Drazen JM 1999. Association between a sequence variant in the IL-4 gene promoter and $\mathrm{FEV}_{1}$ in asthma. Am J Respir Crit Care Med 160: 919-922.

Cantagrel A, Navaux F, Lecoulié PL, Nourhashemi F, Enault G, Abbal M, Constantin A, Laroche M, Mazières B 1999. Interleukin-1 alpha, interleukin-1 receptor antagonist, interleukin-4 and interleukin-1 gene polymorphisms: relationship to occurrence and severity of rheumatoid arthritis. Arthritis Rheum 42: 1093-1100.

Cavassani KA, Tristao FSM, Oliveira LL, Rocha FA, Vancim JO, Moreira AP, Campanelli AP, Panagio LA, Milanezi CM, Martinez R, Rossi MA, Silva JS 2011. Cell-free antigens from Paracoccidioides brasiliensis drive IL-4 production and increase the severity of paracoccidioidomycosis. PLoS ONE 6: e21423.

Choi EH, Charles BF, Taylor JG, Erichsen HC, Chen RA, Walsh TJ, Anttila VJ, Ruutu T, Palotie A, Chanock J 2003. Association between chronic disseminated candidiasis in adult acute leukemia and common IL-4 promoter haplotypes. J Infect Dis 187: 1153-1156.

de Britto T, Franco MF 1994. Granulomatous inflammation. Rev Inst Med Trop Sao Paulo 36: 185-192.

Fitzgerald KA, O'Neill LAJ, Gearing AJH, Callard RE 2001. The cytokine factsbook, 2nd ed., Academic Press, London, 515 pp.

Franco M, Mendes RP, Moscardi-Macchi M, Rezkallah-Iwasso MT, Montenegro MR 1989. Paracoccidioidomycosis. Bailliere's Clin Trop Med Commun Dis 4: 185-219.

Gascan H, Gauchat JF, Roncarolo MG, Yssel H, Spits H, de Vries JE 1991. Human B cell clones can be induced to proliferate and to switch to IgE and IgG4 synthesis by interleukin-4 and a signal provided by activated CD4C T cell clones. J Exp Med 173: 747-750.

Kang BY, Choi YK, Choi WH, Kim KT, Choi SS, Kim K, Ha NJ 2003. Two polymorphisms of interleukin-4 gene in Korean adult periodontitis. Arch Pharm Res 26: 482-486.

Kleinrath T, Gassner C, Lackner P, Thurnher M, Ramoner R 2007. Interleukin-4 promoter polymorphisms: a genetic prognostic factor for survival in metastatic renal cell carcinoma. J Clin Oncol 25: 845-851.

Marques SA 2012. Paracoccidioidomycosis. Clin Dermatol 30: 610-615.

Mello LM, Vergara MLS, Rodrigues VJ 2002. Patients with active infection with Paracoccidioides brasiliensis present a Th2 immune response characterized by high interleukin- 4 and interleukin- 5 production. Hum Immunol 63: 149-154.

Michel J, Gonzáles MJR, Wunderlich D, Diete WA, Hermann JM, Meyle MHJ 2001. Interleukin-4 polymorphisms in early onset periodontitis. J Clin Periodontol 28: 483-488.

Modi WS, O‘Brien TR, Vlahov D, Buchbinder S, Gomperts E, Phair J, O'Brien SJ, Winkler C 2003. Haplotype diversity in the interleukin-4 gene is not associated with HIV-1 transmission and AIDS progression. Immunogenetics 55: 157-164.
Nakayama EE, Meyer L, Iwamoto A, Persoz A, Nagai Y, Rouzioux C, Delfraissy JF, Debre P, Mellroy D, Theodorou I, Shioda T, Seroco Study Group 2002. Protective effect of interleukin-4 -589T polymorphism on human immunodeficiency virus type 1 disease progression relationship with virus load. $J$ Infect Dis 185: 1183-1186.

Nie W, Zhu Z, Pan X, Xiu Q 2013. The interleukin-4 -589C/T polymorphism and the risk of asthma: a meta-analysis including 7,345 cases and 7,819 controls. Gene 520: 22-29.

Pontes CC, Gonzáles JR, Novaes AB, Taba Jr M, Grisi MFM, Michel J, Meyle J, de Souza SLS 2003. Interleukin-4 gene polymorphism and its relation to periodontal disease in a Brazilian population of African heritage. J Dent 32: 241-246.

Restrepo A 1985. The ecology of Paracoccidioides brasiliensis: a puzzle still unsolved. J Med Vet Mycol 23: 323-334.

Rigobello FF, Marquez AS, Lopes JD, Nakanishi-Ito FA, Itano EN 2013. Patients with chronic-form paracoccidioidomycosis present high serum levels of IgE anti-Paracoccidioides brasiliensis Gp70. Mycopathologia 175: 307-313.

Rosenwasser LJ 1999. Promoter polymorphism in the candidate genes, IL-4, IL-9, TGF- $\beta 1$, for atopy and asthma. Int Arch Allergy Immunol 118: 268-270.

Saxena R, Chawla YK, Verma I, Kaur J 2014. Effect of IL-12B, IL-2, TGF- $\beta 1$ and IL-4 polymorphism and expression on hepatitis B progression. J Interferon Cytokine Res 34: 117-128.

Scarel-Caminaga RM, Trevilatto PC, Souza AP, Brito Jr R, Line SRP 2003. Investigation of IL-4 gene polymorphism in individuals with different levels of chronic periodontitis in a Brazilian population. J Clin Periodontol 30: 341-345.

Segal S, Hill AVS 2003. Genetic susceptibility to infectious disease. Trends Microbiol 11: 445-448.

Shikanai-Yasuda MA, Telles Filho FQ, Mendes RP, Colombo AL, Moretti ML, Grupo de Consultores do Consenso em Paracoccidioidomicose 2006. Consenso em paracoccidioidomicose. Rev Soc Bras Med Trop 39: 297-310.

Steinke JW, Borish L, Rosenwasser LJ 2003. Genetics of hypersensitivity. J Allergy Clin Immunol 111: 495-501.

Verra F, Luoni G, Calissano C, Troye-Blomberg M, Perlmann H, Arca B, Sirima BS, Konaté A, Coluzzi M, Kwiatkowski D, Modiano D 2004. IL-4 -589C/T polymorphism and IgE levels in severe malaria. Acta Trop 90: 205-209.

Zhu S, Chan-Yeung M, Becker AB, Dimich-Ward H, Ferguson AC, Manfreda J, Watson WTA, Pare PD, Dandford AJ 2000. Polymorphisms of the IL-4, TNF-alfa and Fce RI $\beta$ genes and the risk of allergic disorders in Aat-risk infants. Am J Respir Crit Care Med 161: 1655-1659. 